\title{
Differences between Solution and Membrane Forms of Chitosan on the In Vitro Activity of Fibroblasts
}

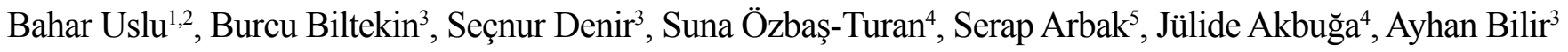 \\ ${ }^{1}$ Department of In Vitro Fertilization, Zeynep Kamil Gynecologic and Pediatric Teaching \& Research Hospital, İstanbul, Turkey \\ ${ }^{2}$ Department of OB/GYN, Yale School of Medicine, New Haven CT, USA \\ ${ }^{3}$ Department of Histology\&Embryology, İstanbul University Faculty of Medicine, İstanbul, Turkey \\ ${ }^{4}$ Department of Biotechnology, Marmara University Faculty of Pharmacy, İstanbul, Turkey \\ ${ }^{5}$ Department of Histology\&Embryology, Acıbadem University Faculty of Medicine, İstanbul, Turkey
}

Background: Chitosan, a linear polysaccharide, has been recently used in biomedical applications. In vitro studies have demonstrated its effect on cellular growth and its stimulatory action on cellular layer formation.

Aims: The present study aims to compare the proliferative effects of chitosan in two forms, membranous and solution forms, on Swiss $3 \mathrm{~T} 3$ mouse embryonic fibroblasts.

Study Design: In vitro study.

Methods: Three experimental groups were formed: cells were cultured in a normal medium without chitosan (Control Group); cells were cultured either in a medium containing $2.0 \%$ chitosan in membranous form (Membrane Group) or chitosan solution at a concentration of $2.0 \%$ (Solution Group). Two different methods were used in the experiments: cells cultured on the medium containing chitosan in solution or membranous forms (method 1); and chitosan solution or membranous forms were added into the medium containing previously cultured cells (method 2).

Results: Scanning electron microscopic investigations of the experimental groups revealed cells with welldefined cellular projections, intact cellular membranes and tight intercellular junctions. They were especially prominent in the membrane group of method 1 and in the membrane and solution groups of method 2. Mouse monoclonal anti-collagen 1 primary antibody was used to indicate collagen synthesis. Prominent collagen synthesis was detected in the membrane groups on the $10^{\text {th }}$ day of culture for both methods. Bromodeoxyuridine (BrdU) and MTT assays were performed in order to assess cellular proliferation and viability, respectively. BrdU labelling tests indicated a higher proliferation index in the membrane group of method 1 on the $5^{\text {th }}$ and $10^{\text {th }}$ days. For the second method, the membranous form on the $10^{\text {th }}$ day and solution form on the $5^{\text {th }}$ day were the most effective groups in terms of cellular proliferation. MTT results reflected a high cellular viability in method 1 on the $5^{\text {th }}$ day of treatment with the membranous form, whereas cellular viability was highest in the solution form of method 2 on the $5^{\text {th }}$ day.

Conclusion: The membranous form of chitosan induced a significant proliferative effect and increased the ratio of cell-to-cell junctions of Swiss 3 T3 mouse embryonic fibroblasts. Conveniently, the solution form also resulted in enhanced cell proliferation and viability compared to the control group. As the solution form is easy to prepare and apply to cells compared to the membrane form, the application of Chitosan directly to media appears to be a convenient alternative for tissue engineering approaches.

Keywords: Cell culture, cell viability, chitosa, collagen immunohistochemistry, scanning electron microscopy, Swiss $3 \mathrm{~T} 3$ 
A key goal of tissue engineering is to use cells, materials, and supporting structures to substitute for damaged tissue and repair its function. For tissue specificity, using appropriate materials for scaffold construction is imperative. An ideal material used for fabricating tissue-engineered scaffolds would provide both structural support and the control of bioactivity. In this regard, chitin-based materials are regarded as appropriate candidates because of their biodegradable properties and ability to be easily fabricated into distinct types of tissue scaffolds. Quaternary ammonium groups that are present within chitin-based materials efficiently interact with the cell. Chitin-based materials can be readily fabricated into many forms of scaffolds, including hydrogels, microcapsules, membranous films, sponges, tubes, and a variety of three-dimensional porous structures (1-4).

Chitosan, a specific moiety of chitin, is a mucopolysaccharide which is used in bioengineering. It is be biocompatible and biodegradable due to cellular lysosomal action. As a non-toxic and non-immunogenic material, its degradation products are not thought to cause any reaction in the body. (1-3,5) Chitosan, being an important biomaterial for use in the treatment of skin damage and burns, has also been reported to increase regeneration processes in the dermis and accelerate wound healing (6-10). Chitosan, which is similar to glycosaminoglycans, has been suggested as a very suitable biomaterial to repair connective tissue (11). Recent studies have revealed the frequent interaction of chitosan and its derivatives with different cell types $(4,12)$.

Chitosan hydrogel can be prepared and cross-linked either covalently or ionically. Covalent cross-linking provides chitosan hydrogel with a permanent architecture that can be used to absorb and release bioactive factors or water. Chitinbased materials and their derivatives are receiving increased attention in tissue engineering because of their unique and appealing biological properties $(4-6,8-10,13,14)$.

Despite numerous primary cell culture studies investigating the effects of chitosan on cellular proliferation, there is little information available about the effects of chitosan on continuous cell lines. Preliminary experiments in our group suggested that the simple addition of soluble chitosan to cell culture media (as opposed to the generation of membranes in culture vessels) had positive effects on cell growth and behaviour.

The present study was designed to investigate the putative effects of a solution form of chitosan on the activity of Swiss 3T3 mouse embryonic fibroblast continuous cell line $(15,16)$, comparing the effects to those induced by membranous chitosan.

\section{MATERIALS AND METHODS}

\section{Experimental groups and methodology}

The effects of chitosan culture in either a membrane or a solution form were evaluated. For each treatment group, we applied chitosan using two different methods, where chitosan was added either before (method 1) or after (method 2) cell plating. Cells were evaluated 5 and 10 days after treatment(s). Each experimental treatment was performed in triplicate. For no-chitosan controls, Swiss 3T3 mouse embryonic fibroblasts (ATCC; Manassas, USA) were cultured in DMEM medium. For the chitosan membrane-treated group, culture plates were prepared with $2.0 \%$ chitosan membrane (the final concentration of solution with DMEM and hydrogel being 1.00\%). For the solution group, chitosan was added directly to media and solubilised to a final concentration of $1.0 \%$.

\section{Swiss 3 T3 embryonic fibroblasts}

Swiss 3T3 embryonic fibroblasts (CCL-92) were provided from American Type Culture Collection (ATCC) Tissue and Cell Culture Laboratory. Mouse embryonic fibroblasts that regularly underwent two passages per week were cultured in Dulbecco's Modified Eagle's Medium DMEM (Sigma 6979; St. Louis, USA) containing penicillin and streptomycin (50 units $/ \mathrm{mL}$ for both) and $10 \%$ bovine serum. Optimal growth was achieved by changing the medium on a daily basis. In both experimental groups, culturing was performed on cell culture plates with 96 wells as $5 \times 10^{3}$ cells/well.

\section{Chitosan scaffolds}

For the solution form, $2.0 \%$ solution Aquasan $\alpha$ - with low molecular weight (AA-101, 75-150 000 Dalton, 85 DD) (Aquasan; Georgia, USA) was prepared with double-distilled water. For a membrane form, chitosan with low molecular weight (150 000 kDa, 81DD) from Fluka (Fluka 50494; Seelze, Germany) was added to a $1.0 \%$ acetic acid solution to solubilise it. All $\mathrm{pH}$ values of prepared materials were adjusted to $\mathrm{pH} 6$ by adding a sodium hydroxide solution. Solutions were sterilised with filters with a $0.22 \mu \mathrm{m}$ pore size (Millipore; Massachusetts, USA). Plates containing chitosan Fluka hydrogel were dried at $40^{\circ} \mathrm{C}$ to achieve chitosan membrane forms.

\section{Scanning electron microscopic (SEM) examination}

Here, 2.5\% glutaraldehyde (Merck; Darmstadt, Germany) was added to cells cultured on microscope slide covers for scanning electron microscopic examination. Following postfixation with $1 \%$ osmium tetroxide (Merck; Darmstadt, Germany) and dehydration in an increasing series of ethyl alcohol, slide covers were placed in a petri dish containing alcohol/ amyl acetate mixtures and pure amyl acetate (Merck; Darmstadt, Germany) series, respectively. 
After drying the tissue samples in a CPD-010 critical point dryer (CPD 010; Balzers Union, Liechtenstein) and gold-coating them with a Sputter Coater Jee-1 (Jeol; Tokyo, Japan), the samples were examined under a 5200 JSM scanning electron microscope (Jeol; Tokyo, Japan).

\section{Immunocytochemistry to detect collagen I synthesis}

To evaluate collagen I synthesis, cells from control and experimental groups were mounted on microscope slide covers (Marienfeld; Lauda-Königshofen, Germany). Immediately after drying at room temperature, slide covers were immersed in $70 \%$ ethyl alcohol. Following evaporation of the fixatives, cells were immersed in a solution of $0.1 \mathrm{M}$ PBS and $0.5 \%$ Triton X-100 (X305) (Sigma; St Louis, USA), then kept in another serum to block non-specific reactions with a serumblocking reagent in serum-A-Histostain Plus Kit (Zymed; Missouri, USA). In the next step, cells were incubated in antimouse collagen I primary antibody-Rabbit polyclonal to collagen 1-ab21286 (Abcam; Cambridge, UK) and then incubated in a solution of secondary antibody (biotinylated secondary antibody-reagent B-Histostain Plus Kit) (Zymed; Missouri, USA).

Following the application of aminoethylcarbazole chromogenic AEC Single Solution (Lab Vision TA 060 SA; Fremont, USA), the microscope slide covers were mounted with ultramount (Labvision; Fremont, USA). Balb/c mouse skin was used for positive and negative control groups. The same collagen immunohistochemistry protocol was applied to thick skin sections $(40 \mu)$ sectioned by cryostat Micro GmbH (HM 500; Berlin, Germany), at $-25^{\circ} \mathrm{C}$. For the positive control, a primary antibody was used, whereas immunocytochemical staining was performed without using a primary antibody for negative control. Collagen immunolabelling was evaluated semi-quantitatively using an additive immunoreactive score reflecting signal intensity as negative $(-)$, mild $(+)$, moderate $(++)$ and strong $(+++)$. All groups were examined and evaluated under a BX 51 light microscope (5060 Wide Zoom Olympus; Tokyo, Japan).

\section{BrdU proliferation assay}

BrdU 20mmol, Lot 30K12928 (Sigma; Schnelldorf, Germany) was prepared according to the protocol and proliferating cells were detected via colorimetric staining. Preparations obtained by light microscopy (Olympus BX51; Tokyo, Japan) were evaluated. The stained nuclei and unstained cells were taken into account as a whole for evaluation purposes. The ratios were calculated between the number of red-stained cell nuclei and the total cell numbers. The values obtained were calculated as \% BrdU (positive). A total of 3000-5000 cells were counted under microscopic examination per treatment group.

\section{Cell viability assays (MTT)}

Viability studies by mitochondrial enzymes which catalyse the reduction of tetrazolium salts is based on a method of cell division, and a xenobiotic, which reflects cytotoxicity by MTT (3-(4,5-dimethylthiazol-2-yl)-2,5difeniltetrazolyum bromide) was used. MTT was used as a quantitative colorimetric method to measure cytotoxicity as well as cell viability.

For MTT analysis, on the $5^{\text {th }}$ and $10^{\text {th }}$ days, $20 \mathrm{ml}$ MTT (Roche; Nonnenwald, Germany) solution (reagent) was added to each plate to microscopically check the formation of formazan crystals. A solution of $200 \mathrm{~mL}$ of DMSO (Sigma; St. Louis, USA) was added to dissolve the crystals. Samples were measured at two spectrophotometric values with a wavelength of OD 550 and $690 \mathrm{~nm}$ (Shimadzu UV-1601 Biospec; Kyoto, Japan). As a blank, a cell-free and medium-free negative control group was used. Chitosan-free cells were used as the positive control group (17).

\section{Statistical analysis}

All statistical analyses were performed using the software programs SPSS 17.0 (SPSS, Chicago, IL, USA) and Excel Tokei 2012 (Social Survey Research Information Co., Tokyo, Japan). Statistical analyses were carried out using nonparametric tests. All data were also descriptively expressed as means \pm SEM. Groups of data were compared with a nonparametric analysis of variance test and pairwise comparisons were carried out using a Mann-Whitney Rank Sum Test while adjusting for multiple comparison. A $\mathrm{p}<0.05$ was considered to be significant, and $\mathrm{p}<0.001$ very significant.

\section{RESULTS}

Data are presented for each treatment group at days 5 (e.g. Figure 1a-f) and 10 (e.g. Figure 1g-l) post-culture. In each case, we describe the control (no chitosan situation), and then evaluate the effects of our different chitosan treatments. The effects of the membrane form versus the solution form of chitosan and the temporal effects of chitosan addition are presented. Assessment of the mitogenic activity of chitosan, especially high-deacetyl forms, found that high rates of mitosis were achieved at a $2.0 \%$ concentration (18-22). We used this concentration in our preliminary experiments to ensure standardisation with those prior studies.

\section{Scanning electron microscopy}

Solution group, method 1

In the solution group, chitosan was added to the media prior to the addition of cells. The control at Day 5 had normal fibro- 

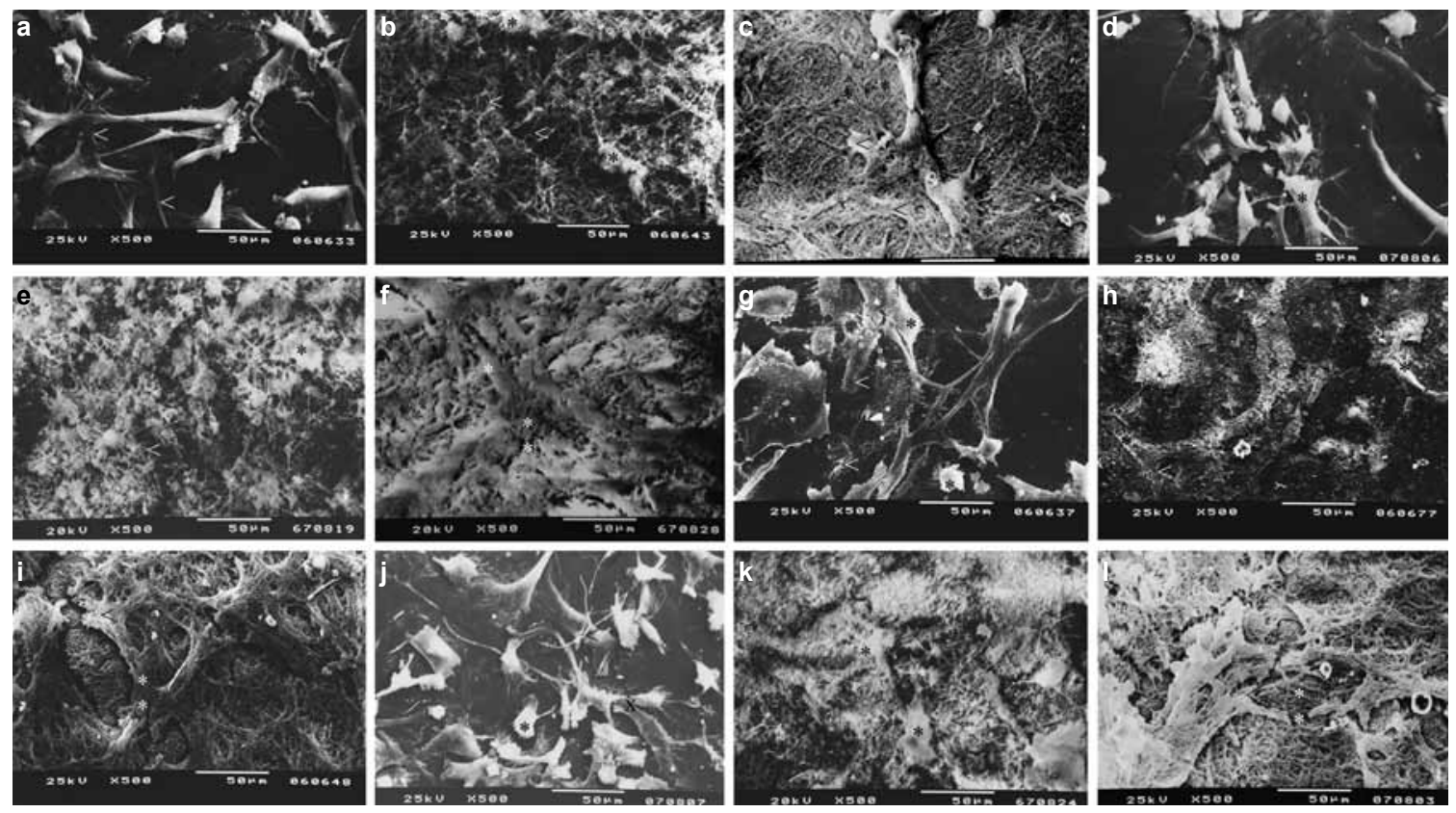

FIG. 1. a-I. SEM pictures method 1: Day 5, the control group: normal morphology and significant extensions in fibroblasts (<) followed (a). Day 5 , the solution group: compared with control cell sizes gets smaller and has a spherical character $\left(^{*}\right)$, an increase in the number of extensions $(<)$ is seen (b). Day 5, the membrane group: located at the base of the cells to contribute to the formation of tissue sticking to chitosan $\left({ }^{*}\right)$, intercellular communication, both extensions (<) and the size of links become evident in the well (c). SEM pictures method 2: Day 5, control group: normal fibroblastic morphology $\left(^{*}\right)(\mathrm{d})$; the solution group: shrunken cells with a spherical morphology $\left(^{*}\right)$.and elaborated extensions $(<)$ (e); the membrane group: chitosan membrane interacted firmly with the cells to provide tight intercellular junctions $\left({ }^{*}\right)$ and compact alignment of cells $\left(^{* *}\right)(f)$. SEM pictures method 1: Day 10, the control group: the cell deaths are increasing rapidly due to contact inhibition $\left({ }^{*}\right)$, and intercellular connections are apparent, separations $(<)$ followed $(\mathrm{g})$. On Day 10, the solution group: group of cells abandoned the spherical forms seen on Day 5 and instead showed signs of tissue organisation $\left({ }^{*}\right)$ and significantly contribute to cell extensions and intercellular communication $(<)$ (h). Day 10, the membrane group: The chitosan membrane accelerated cells and tissue formation to adhere firmly to the base; they reached the three-dimensional form $\left({ }^{* *}\right)$ and a structure compatible with fibroblastic character $(<)$ followed (i). At Day 10, the control group: cellular death $\left({ }^{*}\right)$, a decreased number of cellular extensions $(<)$ and loose intercellular junctions $(x)$ (j); the solution group: elaborate cellular extensions tend to form compact tissue formations and increased the number of cells regaining their proper fibroblastic character $\left({ }^{*}\right)$ along with numerous intercellular junctions $(<)(k)$; the membrane group: compact tissue formation $\left(^{* *}\right)(\mathrm{l})$

blasts cell structure extensions (Figure 1a). With the solution at Day 5, cells appear smaller and more spherical than those of the control group, despite the increase in the number of fibroblast cells. Intercellular extensions began to hold up as an indicator of tissue formation (Figure 1b). On Day 10, the solution group cells became organised into tissue-like structures with increased cell extensions (Figure 1h) compared to control cells on the same day (Figure 1g).

\section{Membrane group, method 1}

The membrane group treated using method 1 also showed signs of increased cellular extensions compared to the no chitosan controls. The cells in the medium with chitosan pieces significantly accelerated the formation of intercellular projections reminiscent of organised tissue (Figure 1c). With the membrane at 10 days, the cells completed the formation of tight attachments in a three-dimensional form (Figure 1i).

\section{Solution group, method 2}

Here, the control group again depicted the normal morphology of fibroblasts at days 5 (Figure 1d) and 10 of the culture (Figure 1j). As a reminder, method 2 cells had chitosan added after cell plating. On the $5^{\text {th }}$ day, the solution group of method 2 reflected an increase in cell number together with changes in cellular morphology, as they were smaller and spherical (Figure 1e). Increased cellular extensions and intercellular adhesions were quite apparent in this group. On the $10^{\text {th }}$ day, the solution group represented a further increase in the number of cellular extensions in fibroblasts which seemed to acquire their characteristic morphology (Figure 1k).

\section{Membrane group, method 2}

In this time period, the membrane group exhibited an increased number of intercellular adhesions with prominent cellular extensions of fibroblasts resulting in a compact tissue formation (Figure 1f). On Day 10, the cells treated with 

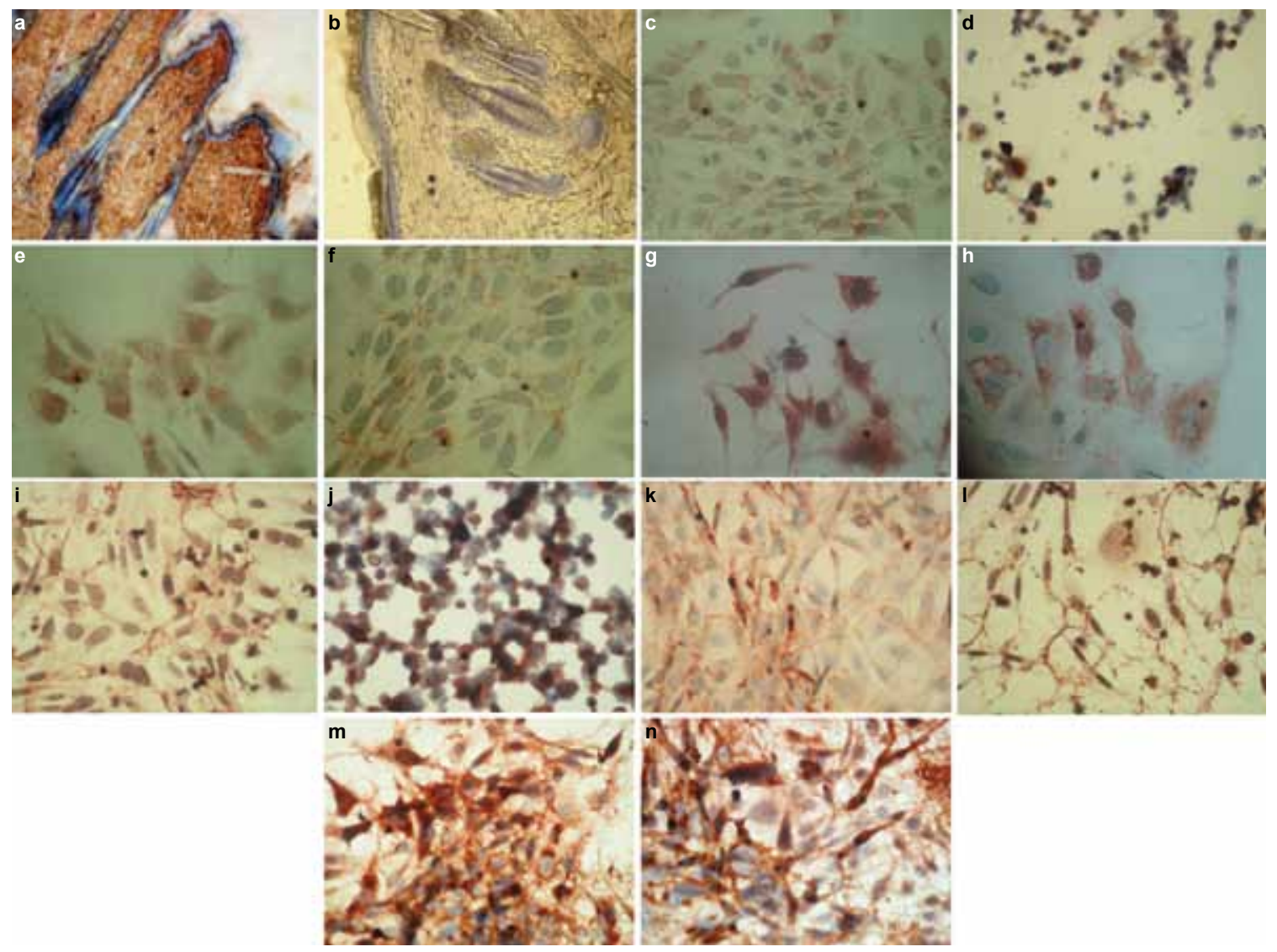

FIG. 2. a-n. Collagen pictures positive \& negative controls: sections from mouse skin as positive control of collagen immunocytochemistry $\left({ }^{* \star}\right)(a)$; negative control of collagen immunocytochemistry $\left.{ }^{* *}\right)($ b). Collagen immunohistochemistry, scale bar: $100 \mu \mathrm{m}$

a) method 1, Day 5, the control group: Intracellular collagen in immunopositive fibroblasts marked (*) are monitored (c). Collagen immunohistochemistry, $x 400$. method 1 , Day 5, the solution group: Positive immuno-stained spherical character winning the collagen in fibroblasts observed in the cell $\left(^{*}\right)(\mathrm{d})$. Collagen immunohistochemistry, $\times 400$. method 1 , Day 5 , the membrane group: fibroblasts $\left({ }^{*}\right)$ are monitored for intensive immunopositive staining (e). Collagen immunohistochemistry, x400. At Day 5: for method 2, the control group: mild collagen immune reactivity is observed in fibroblasts $\left(^{*}\right)(\mathrm{f})$; the solution group: fibroblasts depict significant collagen immunopositivity $\left(^{*}\right)(\mathrm{g})$; the membrane group: fibroblasts with a significant increase in collagen immunopositivity $\left(^{*}\right)(\mathrm{h})$. method 1 , day 10 , the control group: a decrease in fibroblasts immuno-reactivity $\left({ }^{*}\right)$ is noteworthy (i). Collagen immunohistochemistry, $x 400$. method 1 , Day 10 , the solution group: positive-spherical structure of collagen in fibroblasts intense immune staining $\left(^{*}\right)$ is observed (j). Collagen immunohistochemistry, $x 400$. method 1 , Day 10 , the membrane group: fibroblasts significantly increased, collagen immunoreactivity $\left(^{\star}\right)$ is monitored $(k)$. Collagen immunohistochemistry, $x 400$. scale bar: $50 \mu m$. method 2: d) Day 10, the control group: increased cell death together with a prominent decrease in collagen synthesis $\left(^{*}\right)(\mathrm{l})$; the solution group: increased number of fibroblastic cell population with apparent collagen immunopositivity in fibroblasts $\left(^{*}\right)(\mathrm{m})$; the membrane group: closely packed fibroblasts presenting an intense collagen immune positivity $\left(^{*}\right)(\mathrm{n})$. Collagen immunohistochemistry, scale bar: $50 \mu \mathrm{m}$

the chitosan membrane using method 2 were very dense and resembled organised tissue (Figure 11).

\section{Cell organisation and extracellular matrix}

In our SEM studies, the primary effect of chitosan inclusion using either method 1 or 2 was increased cell organisation and dense arrangements resembling tissue. Cell growth appeared increased compared to controls. One factor with powerful effects on cell density and organisation is the composition of the extracellular matrix. We next assessed the deposition of collagen by cells treated with solution or membrane forms of chitosan (again using method 1 and 2) using immunohistochemical staining.

\section{Collagen immunohistochemistry}

Sections from mouse dermis incubated with the primary antibody were used as a positive control for collagen immunocytochemistry (Figure 2a). Sections from the mouse dermis incubated without the primary antibody were used as a negative control of collagen immunocytochemistry (Figure 2b).

For fibroblasts, we found that all groups exhibited immunopositivity for collagen (Figure 2c-n). Among the groups, it appeared that collagen deposition was increased on the $10^{\text {th }}$ day compared to the $5^{\text {th }}$ day (as expected), and that collagen levels were generally higher in the membrane group compared to the solution group and the no chitosan controls. Data are summarised in Table 1. 

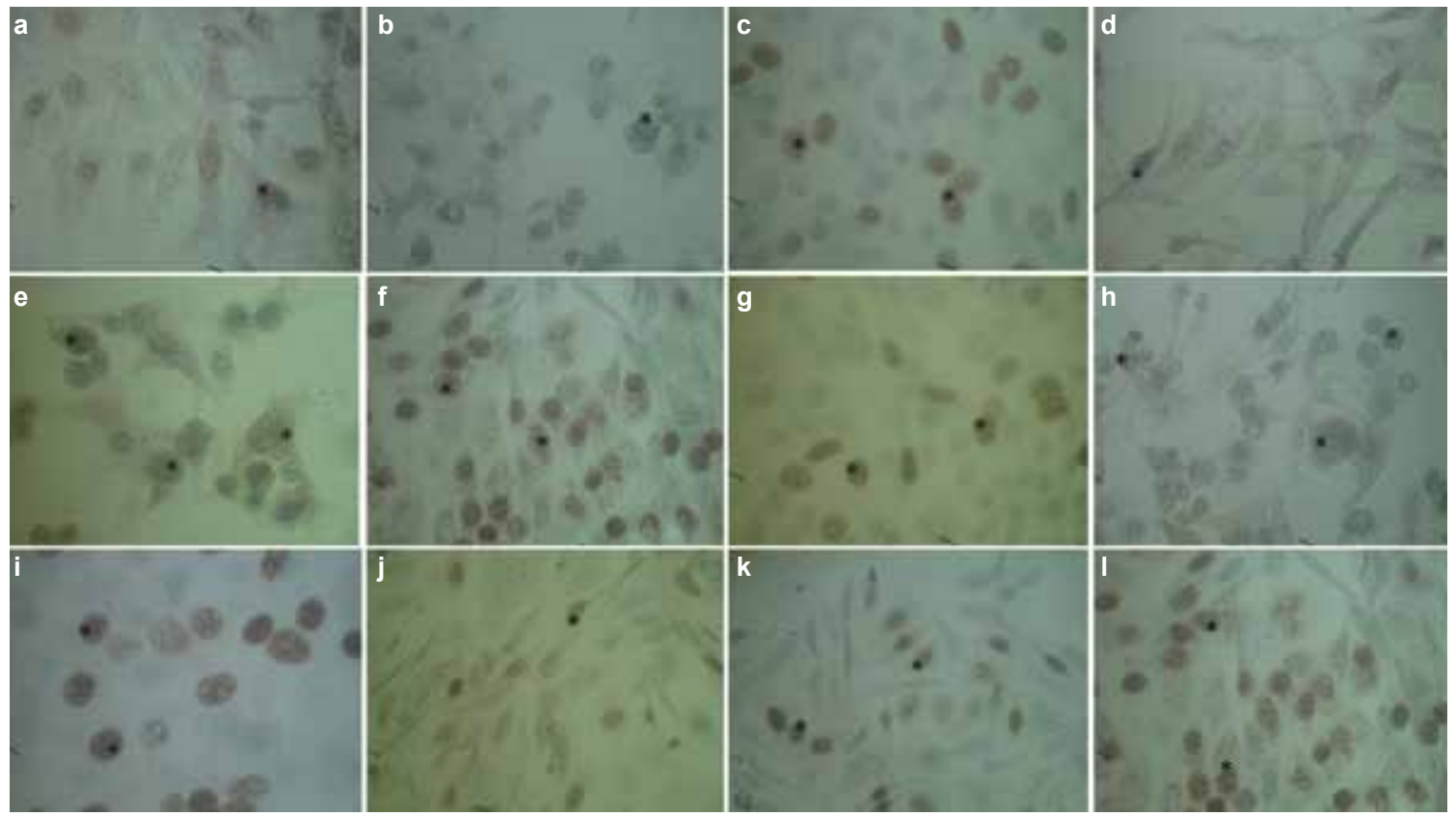

FIG. 3. a-I. BrdU pictures method 1: method 1, 5 days, the control group: BrdU-positive fibroblast cell nuclei $\left({ }^{*}\right)(a)$. BrdU immunohistochemistry, $x 400$. method 1, 5 day, the solution group: BrdU-positive nuclei staining of spherical fibroblasts in the solution group $\left({ }^{*}\right)$ are monitored (b). BrdU immunohistochemistry, $x 400$. method 1,5 days, the membrane group: fibroblasts significantly increased the level of staining of BrdU-positive nuclei $\left(^{*}\right)$ can be seen (c). BrdU immunohistochemistry, x400. method 2: Day 5, the control group: a relatively small size of the immune reaction of BrdU-positive fibroblasts $\left({ }^{*}\right)$ can be seen (d). BrdU immunohistochemistry, $x 400$. Day 5 , the solution group: coarse fibroblasts increased in immune-staining of $\mathrm{BrdU}\left({ }^{*}\right)$ are shown (e). BrdU immunohistochemistry, $\mathrm{x} 400$. Day 5 , the membrane group: increased number of BrdU-positive nuclei a large number of fibroblasts ( $\left.{ }^{*}\right)$ are shown (f). BrdU immunohistochemistry, x400. method 1, 10 days, the control group: the fifth day of the live cell population decreased in the control group and immune staining of BrdU-positive cells (*) can be seen (g). BrdU immunohistochemistry, $\mathrm{x} 400$. method 1, 10 day, the solution group: thrown into a spherical form solution that reduces the clarity of the image in spite of the characterwinning psychic fibroblasts compared with fibroblasts in part the fifth day, an increased immunoreactivity of BrdU-positive $\left(^{*}\right)$ is seen (h). BrdU immunohistochemistry, $x 400$. method 1, 10 day, the membrane group: fibroblasts compared with control and solution groups, observed an increased immunoreactivity of BrdU-positive cells $\left(^{*}\right)(\mathrm{i})$. BrdU immunohistochemistry, $\mathbf{x} 400$. Scale bar: $50 \mu \mathrm{m}$. method 2, Day 10, the control group: a small number of fibroblasts in the immune reaction of BrdU $\left(^{*}\right)$ are shown. BrdU immunohistochemistry, x400 (j). method 2, Day 10, the solution group: showing a significant increase in number of immune staining of BrdU in fibroblasts $\left(^{*}\right)$ ratio has been increasing $(\mathrm{k})$. BrdU immunohistochemistry, $\mathbf{x} 400$. method 2, Day 10, the membrane group: other experimental groups compared to the much increased number of BrdU-positive reactions in the fibroblasts $\left(^{*}\right)$ are shown to be significant (I). BrdU immunohistochemistry, $x 400$. Scale bar: $50 \mu \mathrm{m}$

TABLE 1. Semi-quantitative analysis of immunohistochemical labelling of collagen and all the other labelling analyses

\footnotetext{
Collagen immuno histochemistry

The control group 5 day +

The control group, 10 day +

Method 1, 5 day, the solution Group ++

Method 2, 5 day, the solution Group ++

Method 1, 10 day, the solution Group ++

Method 2, 10 day, the solution Group +++

Method 1, 5 day, the membrane Group ++

Method 2, 5 day, the membrane Group ++

Method 1, 10 day, the membrane Group +++

Method 2, 10 day, the membrane Group +++
}

\section{Cell proliferation and cell death}

In SEM and immunostaining preparations (Figures 1, 2), we noted that control cells lacking the chitosan treatment had decreased numbers of cell extensions and round appearances suggestive of cell death due to contact inhibition. We quantitatively addressed the issues of proliferation and cell death by measuring BrdU incorporation (Figure 3,4) and cell viability (Figure 5), respectively. Our results showed that, overall, chitosan inclusion resulted in increased cell proliferation and viability. In particular, the solution group on the $5^{\text {th }}$ day presented a very high rate of cellular viability. Chitosan inclusion, whether in the membranous form or added directly to media, results in altered, and in many ways improved cell performance.

\section{DISCUSSION}

As determined by SEM imaging, the assessment of collagen expression, and cell proliferation and viability assays, chito- 


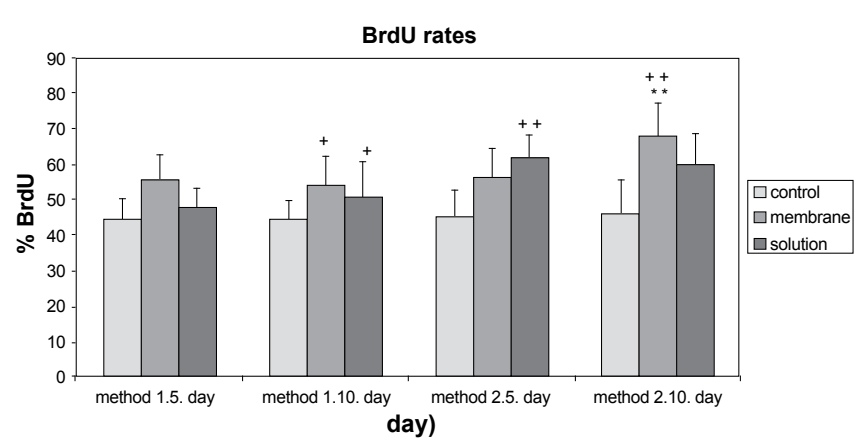

FIG. 4. BrdU graphic (method 1\&2): * $p<0.05$ method 1,10 days, in the solution group, compared to method 1, 5 days, in the solution group; ${ }^{* *} p<0.001$, method 2, 10 days, in the membrane group, compared to method 2, 5 days, in the membrane group; $+p<0.05$ method 1 , 10 days, in the membrane group, compared to method 1, 10 days, in the solution group; $++p<0.001$, method 2,5 days, in the solution group, compared to method 2, 5 days, in the membrane group; ++ $p<0.001$, method 2, 10 days, in the membrane group, compared to method 2, 10 days, in the solution group. The relationship between the methods (method 1 and method 2 ) is considered to be statistically highly significant $(p<0.001)$ according to the Student's t-test

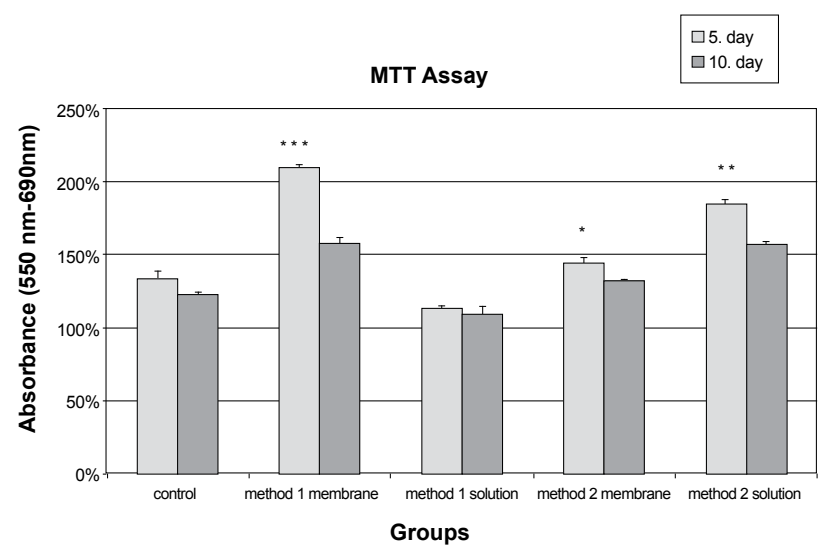

FIG. 5. Cell viability as assessed by MTT assay (method $1 \& 2$ ): * $p<0.01$ method 2,5 days, in the membrane group, compared to method 2,10 days, in the membrane group; ${ }^{*} p<0.001$, method 2,5 days, in the solution group, compared to method 2, 10 days, in the solution group; *** $p<0.001$, method 1,5 days, in the membrane group, compared to method 1, 10 days, in the membrane group. The relationship between the forms (chitosan membrane and solution) and methods (method 1 and method 2) was considered to be statistically highly significant $(p<0.001)$ according to the Student's t-test

san has been shown in our studies to have generally positive effects on cell growth and organisation. Our use of chitosan in a solution form, when added directly to media either before (method 1) or after (method 2) cell addition, is a new and convenient way to deliver the biomaterial to elicit such positive effects.

The literature contains no publications on the solution form despite numerous studies on chitosan membrane. Therefore, we performed an investigation to compare the solution and membrane forms. Interestingly, we observed that the solution form had results close to the results of the membrane form and that, more interestingly, the cells had a spherical character and changed shape, but that their synthesis activities remain unchanged in the solution form.

In general, the scaffold membrane structure, membrane surface charge, protein binding capacity of the surface of the membrane and cell compatibility play an important role in combination with the type of material. However, the property of chitosan to support the different cells, the donor, and the load cell phenotype, deacetylation of chitosan molecular weight, and method of sterilisation may affect the results $(6,23,24)$.

The effects of chitosan on the proliferation of cells in primary cell cultures were widely discussed in numerous studies. Germershaus et al. (25) used trimethyl chitosan as a gene delivery system and suggested it to be the most suitable material for cell culture and gene delivery. Our studies showed similar effectiveness on cell proliferation.

However, there were a limited number of in vitro studies discussing the effects of chitosan in membranes and especially in solution forms on continuous cell lineages. We therefore aimed to plan this current study in consideration of this fact $(1-3,21,26)$.

Chitosan, as a biocompatible mucopolysaccharide, is known to be digested by lysosomal action. There are reports suggesting that its degradation products do not cause any harmful effects in the organism $(2,3,21,26)$. We encountered no toxic reactions in our present study, which correlated with data in the literature $(1-3,21,26)$.

Chitosan is also known for its stimulatory effects on growth factors $(7,27,28)$. This property of chitosan correlated with our results on the $10^{\text {th }}$ day when both solution and membrane forms of chitosan induced fibroblastic cell viability (Figure 5).

Chitosan potency for the synthesis of collagen has been reported in numerous studies. Results of collagen I immunocytochemistry of the present study strongly supported the data from the literature $(18,29)$.

Additional data implicated the chemoactive properties of chitosan, stimulating the proliferation and migration of fibroblasts in the presence of FBS. Our findings demonstrate the related effects of chitosan in both solution and membranous forms of chitosan $(18,30,31)$.

Kong et al. (14), in their tissue engineering studies, suggested that chitosan was the best tissue engineering membrane material. Chuang et al. (32) demonstrated the proliferation effect of a mixture of polyvinyl alcohol (PVA) and 4.0\% chitosan on human fibroblasts (L-929) culture. As a parallel finding, we have demonstrated the significant increase in intercellular adhesion within the membrane group both on the $5^{\text {th }}$ and $10^{\text {th }}$ days. 
Comparing experiments with each group in the Day 5. and 10 , especially at the $10^{\text {th }}$ day, the effect was observed with both membrane and solution forms. Based on the data obtained, both forms have nearly the same effectiveness on cell proliferation, but the chitosan solution form is interpreted to be less effective in terms of adhesion because of its spherical form.

The porous structure of cell growth matrices has been reported to be crucially important for tissue engineering in order to promote cellular adhesion and cellular layering. Wang et al. (24) reported an increased degree of fibroblastic proliferation by using hybrid porous matrices, as a mixture of lowtoxicity solvents and polyglycolide (PGA)-chitosan. We also observed this positive effect of the porous nature of chitosan in the present study. The creation of a spongy porous structure of membranes in vitro in terms of absorptive cells clinging to this structure is a view that would create the appropriate environment. Yan, Zhao, Zhu and colleagues worked on this issue in the field of tissue engineering; this work has been used in studies of organic or nonorganic materials combined with extracellular matrix components and could be obtained if there were more successful results demonstrated (33-35). There are also studies that have been combined with collagen biomaterials $(35,36)$.

Zhu and colleagues prepared solutions of low toxicity-polyglycolide (PGA)-chitosan mixtures. PGA-chitosan matrices enhanced the proliferation of fibroblasts in their studies. The results obtained here showing a spindle-shaped morphology of fibroblast cells are consistent with those findings (37).

In general, hold cells of the membrane structure, membrane surface charge, protein binding capacity of the surface of the membrane and cell compatibility play important roles in combination with the type of material. However, the property of chitosan to support the different cells, the donor and the load cell phenotype, deacetylation of chitosan molecular weight and method of sterilisation may have an effect on the results $(6,23,24)$. Swiss 3 T3 mouse embryonic fibroblast cells used in this sense, showing pre-compliance with the terms of the culture experiments, both in the experimental stage and the convenience of use in this regard, led to identification of the molecular structure of the organic material chitosan.

It is strongly believed that cellular phenotype, type of biomaterial, the nature of the medium, protein absorbance values, and surface charge of the cell membrane are strictly effective in cell culture $(33,34,38,39)$. Serum has been added to chitosan biomaterial in numerous studies in order to promote cellular proliferation $(20,31,40)$. However, regarding the data of our current study, we suggested the effectiveness of serumcontaining chitosan biomaterials (especially in membrane form) to synergistically increase cellular adhesion, due to the presence of cations, such as $\mathrm{Ca}^{2+}$ and $\mathrm{Mg}^{2+}$, by increasing the chemoactive properties of chitosan and the surface charge.
There have been contradictory studies demonstrating both the stimulatory $(11,18)$ and inhibitory effects $(23,28)$ of chitosan on fibroblastic activity. We believe that this contradiction is the result of several factors, including cell population, method used, and the chemical properties of chitosan and its derivatives. Focusing mainly on the response of chitosan to variable preparatory conditions, the present study could contribute to further studies in related fields.

In accordance with prior studies, we can conclude that chitosan, in its membrane form, is highly effective in promoting cell organisation and adhesion, collagen synthesis, and cell proliferation and viability in the Swiss 3 T3 mouse embryonic fibroblasts continuous cell line. On the $10^{\text {th }}$ day of the experiment, the membranous form of chitosan induced significant proliferative effects and increased the ratio of cell-to-cell junctions of Swiss 3 T3 mouse embryonic fibroblasts under in vitro conditions.

Our work with the solution form of chitosan has not been reported previously for these types of experiments. Solutions of chitosan are easier and faster to prepare, and there is less variability from solution to solution compared to membrane preparations. The solution form may be a good alternative for the following reasons: the chitosan particles in solution favour cells taking on spherical shapes, a feature that may prove useful for specific applications. They offer control of when fibroblasts are attached to the culture dish, as we found that cell viability and proliferation were normal, but cell attachment was delayed for several days. Cells treated with the solution form may also interact with the particles in a way that makes cell feeding or drug delivery easier. Larger scale studies are now necessary to evaluate the utility of this inclusion of chitosan.

\section{Ethics Committee Approval: N/A.}

\section{Informed Consent: N/A.}

Peer-review: Externally peer-reviewed.

Author contributions: Concept - B.U., S.A., A.B.; Design - S.A., J.A., A.B.; Supervision - S. A.; Resource - B.B., S.D., B.U.; Materials - B.B., S.O.T.; Data Collection\&/or Processing - B.B., S.D., B.U.; Analysis\&/or Interpretation - B.U.; Literature Search - B.U., S.A.; Writing - B.U.; Critical Reviews - A.B.

Conflict of Interest: No conflict of interest was declared by the authors.

Financial Disclosure and Acknowlegdements: The study has been received financial support from TUBITAK (The Scientific and Technological Research Council of Turkey) (SBGA-104S516) and Dr. Joshua Johnson from Yale School of Medicine. 


\section{REFERENCES}

1. Akbuga J. A Biopolymer: Chitosan. Int J Pharm 1995;1:3-18.

2. Koide S. Chitin-chitosan: properties, benefits and risks. Nutrition Research 1998;18:1091-1101. [CrossRef]

3. Hwang SM, Chen CY. Chitinous materials inhibit nitric oxide production by activated RAW 264.7 macrophages. Biochem Biophys Res Commun 2000;271:229-33. [CrossRef]

4. Yang TL. Chitin-based Materials in Tissue Engineering: Applications in Soft Tissue and Epithelial Organ. Int J Mol Sci 2011;12:1936-63. [CrossRef]

5. Aral C, Akbuga J. Alternative approach to the preparation of chitosan beads. Int J Pharm 1998;168:9-15. [CrossRef]

6. Wan Y, Wu H, Wen D. Porous-conductive chitosan scaffolds for tissue engineering, 1. Preparation and characterization. Macromol Biosci 2004;16:882-90. [CrossRef]

7. Ueno H, Nakamura M, Murakami M. Evaluation effects of chitosan for the extracellular matrix production by fibroblasts and the growth factors production by macrophages. Biomaterials 2001;22:2125-30. [CrossRef]

8. Pereira F, Pereira C, Lacerda MH. Contact dermatitis due to a cream containing chitin and a Carbitol. Contact Dermatitis 1998;38:290-1. [CrossRef]

9. Stone CA, Wright H, Clarke T, Powell R, Devaraj VS. Healing skin graft donor sites dressed with chitosan. Brit J Plast Surg 2000;53:601-6. [CrossRef]

10. Denuziere A, Ferrier D, Damour O, Domard A. Chitosan-chondroitin sulfate and chitosan-hyaluronate polyelectrolyte complexes: biological properties. Biomaterials 1998;19:1275-85. [CrossRef]

11. Muzzarelli R, Baldassarre V, Conti F, Ferrara P, Biagini G, Gazzanelli $\mathrm{G}$, et al. Biological activity of chitosan: ultrastructural study. Biomaterials 1988;9:247-52. [CrossRef]

12. Tahara K, Sakai T, Yamamoto H, Takeuchi H, Hirashima N, Kawashima Y. Improvements in transfection efficiency with chitosan modified poly(DL-lactide-co-glycolide) nanospheres prepared by the emulsion solvent diffusion method, for gene delivery. Chem Pharm Bull 2011;59:298-301. [CrossRef]

13. Diao ZY, Fu HL, Nie CL, Hao LJ, Yang DP, Chen WH. Controlled release of transforming growth factor-beta receptor kinase inhibitor from thermosensitive Chitosan-based hydrogel: application for prevention of capsular contracture. Chin Med J (Engl) 2011;124:284-90.

14. Kong LJ, Ao Q, Xi J, Zhang L, Gong YD, Zhao NM, et al. Proliferation and differentiation of MC 3T3-E1 cells cultured on nanohydroxyapatite/chitosan composite scaffolds. Sheng $W u$ Gong Cheng Xue Bao 2007;23:262-7. [CrossRef]

15. Aaronson SA, Todaro GJ. Development of 3T3-like lines from Balb/c mouse embryo cultures. Transformation susceptibility to SV40. J Cell Physiol 1968;72:141-8. [CrossRef]

16. Chen RH, Tsaih ML. Effect of temperature on the intrinsic viscosity and conformation of chitosan in dilute HCI solution. Int $J$ Biol Macromol 1998;23:135-41. [CrossRef]

17. Mosmann T. Rapid colorimetric assay for cellular growth and survival: application to proliferation and cytotoxicity assays. J Immunol Methods 1983;16:55-63. [CrossRef]
18. Howling GI, Dettmar PW, Goddard PA, Hampson FC, Dornish M, Wood EJ. The effect of chitin and chitosan on the proliferation of human skin fibroblasts and keratinocytes in vitro. Biomaterials 2001;22:2959-66. [CrossRef]

19. Senel S, McClure SJ. Potential applications of chitosan in veterinary medicine. Adv Drug Deliv Rev 2004;56:1467-80. [CrossRef]

20. Kiyozumi T, Kanatani Y, Ishihara M, Saitoh D, Shimizu J, Yura $\mathrm{H}$, et al.The effect of chitosan hydrogel containing DMEM/F12 medium on full-thickness skin defects after deep dermal burn. Burns 2007;33:642-8. [CrossRef]

21. Ding SJ. Biodegradation behavior of chitosan/calcium phosphate composites. J Non-Cryst Solids 2007;353:2367-73. [CrossRef]

22. Abdel-Fattah WI, Jiang T, El-Bassyouni Gel-T, Laurencin CT. Synthesis, characterization of chitosans and fabrication of sintered chitosan microsphere matrices for bone tissue engineering. Acta Biomater 2007;3:503-14. [CrossRef]

23. Berscht PC, Nies B, Liebendörfer A, Kreuter J. Incorporation of basic fibroblast growth factor into methyl pyrrolidinone chitosan fleeces and determination of the in vitro release characteristics. Biomaterials 1994;15:593-600. [CrossRef]

24. Wang YC, Lin MC, Wang DM, Hsieh HJ. Fabrication of a novel porous PGA-chitosan hybrid matrix for tissue engineering. Biomaterials 2003;24:1047-57. [CrossRef]

25. Germershaus O, Mao S, Sitterberg J, Bakowsky U, Kissel T. Gene delivery using chitosan, trimethyl chitosan or polyethylenglycol-graft-trimethyl chitosan block copolymers: establishment of structure-activity relationships in vitro. J Control Release 2008;125:145-54. [CrossRef]

26. Shen JY, Pan XY, Lim CH, Chan-Park MB, Zhu X, Beuerman RW. Synthesis, characterization, and in vitro degradation of a biodegradable photo-cross-linked film from liquid poly(epsiloncaprolactone-co-lactide-co-glycolide) diacrylate. Biomacromolecules 2007;8:376-85. [CrossRef]

27. Yao F, Chen W, Wang H, Liu H, Yao K, Sun P, Lin H. A study on cytocompatible poly(chitosan-g-L-lactic acid). Polymer 2003; 44:6435-41. [CrossRef]

28. Mori T, Okumura M, Matsuura M, Ueno K, Tokura S, Okamoto $\mathrm{Y}$, et al. Effects of chitin and its derivatives on the proliferation and cytokine production of fibroblasts in vitro. Biomaterials 1997;18:947-51. [CrossRef]

29. Norazril SAH, Aminuddin BS, Norhayati MM, Mazlyzam AL, Fauziah O, Ruszymah BH. Comparison of chitosan scaffold and chitosan-collagen scaffold: a preliminary study. Med J Malaysia 2004;59:186-7.

30. Ishihara M, Ono K, Sato M, Nakanishi K, Saito Y, Yura H,et al. Acceleration of wound contraction and healing with a photocrosslinkable chitosan hydrogel. Wound Repair Regen 2001;9:513-21. [CrossRef]

31. Ma J, Wang H, He B, Chen J. A preliminary in vitro study on the fabrication and tissue engineering applications of a novel chitosan bilayer material as a scaffold of human neofetal dermal fibroblasts. Biomaterials 2001;22:331-6. [CrossRef]

32. Chuang WY, Young TH, Yao CH, Chiu WY. Properties of the poly (vinyl alcohol)/chitosan blend and its effect on the culture of fibroblast in vitro. Biomaterials 1999;20:1479-87. [CrossRef] 
33. Yan YH, Cui J, Chan-Park MB, Wang X, Wu QY. Systematic studies of covalent functionalization of carbon nanotubes via argon plasma-assisted UV grafting. Nanotechnology 2007;18:115712. [CrossRef]

34. Zhao F, Yin Y, Lu WW, Leong JC, Zhang W, Zhang J, et al. Preparation and histological evaluation of biomimetic three-dimensional hydroxyapatite/chitosan-gelatin network composite scaffolds. Biomaterials 2002;23:3227-34. [CrossRef]

35. Zhu Y, Chan-Park MB. Density quantification of collagen grafted onto biodegradable polyester: its application to esophageal smooth muscle cell. Anal Biochem 2007;363:119-27. [CrossRef]

36. Wang XP, Ye JD, Chen L, Wang YJ. Microstructure and properties of a calcium phosphate cement tissue engineering scaffold modified with collagen and chitosan. Bioceramics 2007;983-6.
37. Zhu AP, Fang N, Chan-Park MB, Chan V. Adhesion contact dynamics of 3T3 fibroblasts on poly (lactide-co-glycolide) surface modified by photochemical immobilization of biomacromolecules. Biomaterials 2006;27:2566-76. [CrossRef]

38. He B, Wan E, Chan-Park MB. Synthesis and Degradation of Poly $(\alpha, \beta$-malic acid) Based Biodegradable Hydrogel. Chem Mater 2006;18:3946-55. [CrossRef]

39. Malette WG, Quigley HJ, Gaines RD, Johnson ND, Rainer WG. Chitosan: a new hemostatic. Ann Thorac Surg 1983;36:55-8. [CrossRef]

40. Ma L, Gao C, Mao Z, Zhou J, Shen J, Hu X, Han C. Collagen/ chitosan porous scaffolds with improved biostability for skin tissue engineering. Biomaterials 2003;24:4833-41. [CrossRef] 